\title{
Introduction to Technology in Transition
}

\author{
SHERRILYN K. FISHER \\ Wyandotte Comprehensive Special Education Cooperative \\ J. EMMETT GARDNER \\ University of Oklahoma
}

\begin{abstract}
The recent changes in legislation concerning technology and transition have brought the two fields into national attention. New thinking by professionals, parents, and students about the application of technology is now required by the fact that (a) technology must be considered in every individualized education plan, (b) students are to receive services to enable them to be educated in the regular curriculum to the maximum extent possible, and (c) related services (including assistive technology) are to be considered as part of students' transition plans. This article explores an integrated approach to technology and transition in historical and current perspectives, and provides an introduction and philosophical base for the articles which follow in this special issue.
\end{abstract}

In 1997 when we first proposed this topical issue on technology and transition to the Board of the Division of Career Development and Transition (DCDT), we were met with enthusiasm about examining assistive and instructional technology and its impact on the transition process. After nearly two years of preparation, we remain excited about this issue of CDEI and are pleased with the end product. This issue represents the first group of authors to present ideas that correlate and integrate the fields of technology and transition. The writing comes at an optimum time-a juncture that roughly coincides with legislation requiring technology to be considered for every student with a disability. The juncture also is a critical one; it is a time when many practitioners have not yet developed the expertise to knowledgeably "consider" technology and specify related solutions, and indeed, are unaware of even general technology benefits for their students.

Moreover, with the urgency of transition planning already upon us, we must extend our thinking to the vital integration of technology benefits into this important process. The opportunities that technology can provide afford students and young adults alike access to social relationships and careers that were heretofore unavailable. 
With that thought in mind, this issue provides a compilation of articles designed to raise the awareness level of preservice providers, professionals, parents, and students about the use of technology in transition planning. We believe that the time has come to present important issues and provide literature which demonstrates that a wide variety of technology applications can be used and merged into transition planning.

This article begins by briefly examining the historical path that has led to current practice. Following this discussion, we point out similarities and perspectives that both fields have in common. Throughout the narrative we provide an overview of the articles to follow. Finally, we examine the impact and implications of the shared horizons of transition and technology.

\section{TRENDS In TECHNOLOGY AND TRANSITION}

This is indeed a "transitional" time for technology and transition planning in the field of special education. Heightened awareness of the potential of technology in special education has been gaining momentum over the last two decades. It is interesting to observe that as the first signs of technological advances in the field of disabilities were being heralded in the early and middle 1980s (e.g., Behrmann, 1984; Blackhurst \& Hofmeister, 1980; Ellis \& Sabornie, 1986; Hasselbring, Goin, \& Bransford, 1988; Jordan \& Thomas, 1982; Rieth, Bahr, Polsgrove, Okolo, \& Eckhert, 1987), the field of special education also was in the midst of articulating and developing principles of transition and career education.

Madeline Will's (1984) call for transition legislation first put into a national focus the need for bridging school to work for all students with disabilities. With this impetus, both the definition and role of transition services expanded in the literature (e.g., Clark \& Knowlton, 1987; Halpern, 1985; Razeghi, Kokaska, Gruenhagen, \& Fair, 1987). Significant research had clearly demonstrated that students and adults with disabilities were not able to enjoy the full rights of citizenship nor participate fully in the American dream (e.g., Hasazi, Gordon, \& Roe, 1985: Mithaug, Horiuchi, \& Fanning, 1985; Zigmond \& Thornton, 1985). The barriers included unemployment, underemployment, poor access to post secondary education and training, little social interaction, insufficient agency assistance, few options for recreation and leisure, and limited personal satisfaction. All were issues that greatly affected the quality of life for individuals with disabilities.

In the rush to put into place the philosophical base and legislation that would address some of these barriers, the period of 1975 to 1988 became a time of disequilibrium. It was a period when the field of special education was progressing well in defining principles and methodologies of transition services, and instructional and assistive technology (AT), but lacking clear 
direction in legal policies. Even today, research in the area of AT points out that though general guidelines have been written by states, specific guidelines on its implementation reveal a considerable variance in development and clarification (Bell \& Blackhurst, in press; Reid, 1994). Lacking guidance from states, local education agencies were left with ambiguous direction regarding assistive technology (AT) and practitioners had little direction on devices that would assist students in their learning.

From a historical perspective, the antecedents of federal legislation impacting on the provision of AT can be traced as far back as the authorization of sections 503 and 504 of the Rehabilitation Act of 1973, and the Education for All Handicapped Children Act of 1975 (EHA) (P.L. 94-142). Both laws established pivotal concepts of reasonable accommodation and least restrictive environment ( $\mathrm{LRE}$ ), which in turn opened the door for AT devices and services to be considered as possible and reasonable methods to provide persons with disabilities access to employment, public education, and postsecondary opportunities (Cook \& Hussey, 1995). It is important to point out that in neither EHA nor the Rehabilitation Act did the terms AT devices or service exist. Rather, technology was an implied educational component based on interpretation of key provisions in the laws at that time. For example, when AT was provided, the services usually fell under the auspices of a supplemental aid or service deemed essential to support a student in the classroom and/or to insure that LRE was being provided (Hager, 1998; Julnes \& Brown, 1993).

The historical provisions of federal legislation impacting transition on the other hand, were far more numerous and extensive than those for AT. For example, the Rehabilitation Act of 1973 resulted in major emphasis on services for adolescents and adults with disabilities, including the identification of work-study services, career development, and employment practices as areas requiring attention and action. Section 504 of The Rehabilitation Act also supported vocational education, training and employment for students with disabilities by assuring equal access to these opportunities, along with accommodations to make the passage to these opportunities possible.

In the $1980 \mathrm{~s}$, Section 626 of the 1983 Amendments to EHA specifically required the distribution of annual contracts and grants to strengthen and coordinate the education, training and related services for this population. Other actions, including The Carl Perkins Vocational Education Act of 1984 and The Rehabilitation Act Amendments of 1992, emphasized transition goals of education, work, and community participation.

Figure 1 provides a timeline of these major pieces of legislation. It should be noted that the economy has been a major force behind transition legislation, agency policies and procedures. A current example of how educa- 
Figure 1.

Some Key Events in Transition and Technology.

\begin{tabular}{|c|c|}
\hline Date/Event & Impact on Field of Transition \\
\hline $\begin{array}{l}\text { 1963. Vocational } \\
\text { Educational of } 1963\end{array}$ & $\begin{array}{l}\text { Mandated that students with disabilities } \\
\text { who have disabilities have opportunity } \\
\text { to attend vocational classes. }\end{array}$ \\
\hline $\begin{array}{l}\text { 1973. Rehabilitation } \\
\text { Act of } 1973 . \\
\text { Sections } \\
503 \text { and } 504\end{array}$ & $\begin{array}{l}\text { Identification of vocational education, } \\
\text { work-study services, career development } \\
\text { and employment practices as areas } \\
\text { requiring attention and action. Equal } \\
\text { access to employment opportunities. }\end{array}$ \\
\hline $\begin{array}{l}\text { 1975. Education } \\
\text { of All Handicapped } \\
\text { Children's Act (EHA) } \\
\text { (PL 94-142) } \\
\text { of } 1975\end{array}$ & $\begin{array}{l}\text { Principle of least restrictive environment } \\
\text { opened the door for students with } \\
\text { disabilities in all the major transition } \\
\text { areas associated with public schools, } \\
\text { including academics, work-study } \\
\text { programs, social/leisure interactions, } \\
\text { and post-secondary preparation. }\end{array}$ \\
\hline $\begin{array}{l}\text { 1983. Amendments } \\
\text { to EHA Section } 626 \\
\text { (PL 98-199) }\end{array}$ & $\begin{array}{l}\text { Addressed difficulties in the transition } \\
\text { to adult life for youth with disabilities, } \\
\text { targeting OSERS to distribute } 6.6 \\
\text { million in annual contracts and grants } \\
\text { to strengthen and coordinate the } \\
\text { education, training and related services } \\
\text { for this population }\end{array}$ \\
\hline
\end{tabular}

1984. Carl Perkins
Vocational
Education.
Act of 1984

1984. OSERS

Program for the Transition of Youth with Disabilities

1988. Technology

Related Assistance Act of 1988

(The Tech Act)

(PL 100-407)
$57 \%$ of the funds allocated to states

for vocational education must be spent on special groups, and include the delivery of assessment, support services,counseling and vocational education and transitional services for students with disabilities.

Called for federal legislation to pursue transition services, bridging school to work for students with disabilities.

Assistive technology as a related service became more available to students who needed accommodation to succeed in the transition environments of school and work.
Impact on Field of Technology Applications

Pioneered the idea that some students with disabilities might be successful in technical vocational classes

Principle of reasonable accommodation to employment, public education and post-secondary opportunities covered technology-based assistance (Cook \& Hussey, 1995).

Principle of least restrictive environment to public education covered technology assistance (Cook \& Hussey, 1995). Supplementary aids and service covered what is now defined as assistive technology devices and services (Hager, 1998).

Paved the way for inclusion in technical vocational preparation for a greater number of students with disabilities.

Established a systems change program of state-wide technology assistance centers for assistive technology consumers (Cook \& Hussey, 1995). Clearly and directly defined assistive technology devices and assistive technology services, and identified then as part of the continuum of services for persons with disabilities (Galvin \& Wodshall, 1996). 


1990. Individuals
with Disabilities
Education Act (IDEA)
(PL 101-476)

1990. Carl D. Perkins Vocational and Applied Technology Education Act

1990. Americans with Disabilities Act (ADA)
Transition planning and services were clearly and legally defined and required as part of the individual education planning (IEP) process and document.

Mandates that special populations have equal access to recruitment, enrollment, placement, and the full range of vocational programs.

Gave individuals with disabilities the right to access equal opportunities to jobs and transportation.
1991. Secretary's Commission on Achieving Necessary Skills (SCANS)

1992. The

Rehabilitation

Act Amendments of 1992

1994. U.S. Department Extended the concept of transition of Education. School- to additional learners, including to-Work Opportunities disadvantaged, migrants, minority Act of 1994, P.L. 103-239.

1997.

Reauthorization of IDEA.

Specified skills to be learned in school which affect work and adult roles.

Emphasized transition goals of education, work and community participation for populations with disabilities.

groups and gifted.

For students starting at age 14 , reiterates the requirement of the transition statement and sevices which focus on the courses of study. At age 16 or younger, demands interagency responsibilities and linkages that promote movement through the seven major transition environments. Includes related services in the definition for the first time, thus linking assistive technology and transition.

1998. Section 508 of Provides equal access to information The Rehabilitation Act 29 U.S.C. $\$ 798$ that may be necessary to succeed in various transition environments.
Equal access at times demands assistive technology and accommodations for individuals with disabilities.

Although assistive technology is not specifically defined, ADA's definition of "auxiliary aids and services" includes assistive technology as a form of support to assure equal access to school and job programs (Golden, 1998).

Emphasized the importance of technology in accessing information.

Provided assistive technology to help qualified individuals reach career goals.

Equal access to the full range of technical preparation programs to special populations.

Included an expanded definition of assistive technology services, and the requirement that the IEP planning process must consider whether a child needs an assistive technology device or services.

Includes accommodations necessary to make public information accessible to persons with disabilities.

Note: For more detailed discussions regarding the history of key federal and policy events in the areas of technology and transition, see: Clark \& Kolstoe (1995), Cook \& Hussey (1995) and Galvin \& Wodshall (1996). 
tion, the economy and transition are affected by politics is found in the Policy Directive (RSA-PD-97-04) issued by The Rehabilitation Services Administration (RSA), which oversees state vocational rehabilitation (VR) agencies. This new directive requires VR agencies to approve vocational goals and the services to meet goals which enable persons with disabilities to maximize their employment potential, rather than provide mere entry level jobs. The directive goes on to state that in many cases, trial work or educational placements should be accompanied with the provision of AT as a means of overcoming a disability-related deficit (Hager, 1998).

In the 1990 s, we find that transition is not only a federal requirement, but a way to connect systems, provide structure for curriculum, and a political movement (Apple \& Zenk, 1996). AT also has its roots in political motivation, for the premise of equal opportunity and access is one in which most Americans believe. From this premise, political actions such as Section 504 of the Rehabilitation Act of 1973, Americans with Disabilities Act of 1990, and Technology Related Assistance Act of 1988 (P.L. 100-407) emerged. An example of how policy directives affect the distribution of AT is found in the 1998 Medicaid brochure, written for parents of children with disabilities. The brochure states "...AT is provided as needed to enhance or complete other services provided to your child and belongs to your child."(Adult and Medical Services Commission of the Kansas Department of Social and Rehabilitation Services, July, 1998). For special education budgets the implications are enormous: If a school district receives any Medicaid money and purchases a device for a specific child, the device goes with the child wherever she or he might move.

Though linked in political philosophy and legislation, the disciplines of technology and transition remained relatively separate from one another through the late 1980's, with each field working to establish its acceptance and practices within special education. Collaborative planning between transition and technology is long overdue, especially in the light of legislative actions which occurred in the period between 1988 and 1990, fundamentally linking the fields of technology and transition. These actions and their impact on mutual perspectives of transition and technology are examined in the next section.

\section{Clarifying and Defining Definitions In Transition and AT}

The first significant breakthrough for AT in legislation and policy came with the passage of The Technology Related Assistance Act (1988). In addition to establishing a systems change program of statewide technology assistance centers for AT consumers (Cook \& Hussey, 1995), for the first time, AT and services became clearly and directly identified as part of the con- 
tinuum of services for persons with disabilities (Galvin \& Wodshall, 1996). The Technology Related Assistance Act (1988) also established a legal definition of AT and AT services and instituted provisions that identified and defined the selection, acquisition, or use of AT services, by specifying a broad spectrum of services. Table 1 provides a summary of these services.

The second major breakthrough in legislation came with the passage of The Individuals with Disabilities Education Act of 1990 (P.L. 101-476), which included landmark stipulations regarding transition planning and services. For the first time, transition planning of services for persons with disabilities was clearly and legally defined; most importantly, it was required as part of the Individual Education Plan (IEP) process. In much the same way the Technology Related Assistance Act (1988) defined AT devices and services, IDEA (1990) included a wide spectrum to define transition and transition-related services. Table 2 provides a listing of these services.

The 1997 Amendments of IDEA addressed both AT and transition in new and direct ways, but still without any explicit merger of the two principles. IDEA expanded its definition of AT services, clearly stating that if AT was needed to insure a child's free and appropriate education, it was to be provided. With respect to IEPs, IDEA stated that the IEP team must consider whether a child needs an AT device or services. The 1997 Amendments also provided strong directives regarding transition planning and AT as part of students' individualized education. Specifically, IEP teams must include goals and objectives in the major areas of transition services, or provide justification why they are not addressed (see Table 1 ). Thus, language in IDEA allowed a reasonable interpretation: When a child reaches the age that transition planning begins, beginning then and on each subsequent IEP, consideration of AT devices and services could be a part of the yearly IEP process. In fact, the definition of transition services was amended to add related services to the types of services to be provided, thereby removing any doubt that transition services may include AT.

Unfortunately, there are differences in the way in which IEP teams are required to document provisions of transition planning and AT. In the case of AT, the team is only required to "consider" AT, and not specify the listing of different instructional areas that might prompt the team to look very specifically at technology assistance. The requirement is only to justify an AT device or service if it is needed. Clearly, transition services are given greater emphasis, with firm guidelines for inclusion in the IEP, while the inclusion of AT is stated more ambiguously with the wording "if needed."

As the critical need for legal definitions and clarification of services became increasingly apparent during the 1990 's, professionals in both transition and technology fields were working to further define and broaden the definitions and practices associated with transition (e.g., Berkell \& 
Table 1.

Key Legislative Definitions in Technology and Transition

Definitions of Assistive Technology (AT) Devices and Services:

The Technology Act (P.L. 100-407)

AT Device

"any item, piece of equipment, or product system whether acquired commercially off the shelf, modified or customized, that is used to increase, maintain, or improve functional capabilities of individuals with disabilities."

\section{AT Services}

"any service that directly assists an individual with a disability in the selection, acquisition or use of an AT device."

Definitions of AT Devices and AT Services (\$101. Amendments to IDEA, 1997)

$\$ 300.5$ AT Device (1997)

The same definition as above (P.L. 100-407)

$\$ 300.6$ AT service (1997)

"any service that directly assists a child with a disability in the selection, acquisition, or use of an AT device."

Definitions of AT Devices and Services: The Technology ACT (P.L. 100-407)

Such term includes-

(a) the evaluation of the needs of a child with a disability, including a functional evaluation of the child in the child's customary environment;

(b) purchasing, leasing, or otherwise providing for the acquisition of AT devices by children with disabilities;

(c) selecting, designing, fitting, customizing, adapting, applying, maintaining, repairing, or replacing $\mathrm{AT}$ devices;

(d) coordinating and using other therapies, interventions, or services with AT devices, such as those associated with existing education and rehabilitation plans and programs;

(e) training or technical assistance for a child with a disability or, if appropriate, that child's family; and

(f) training or technical assistance for professionals (including individuals providing education or rehabilitation services), employers, or other individuals who provide services to, employ, or are otherwise substantially involved in the major life functions of that child

Definition of Transition: (PL 101-476)

"a coordinated set of activities for a student, designed within an outcome process, that promotes movement from school to post-school activities, including post-secondary education, vocational training, integrative employment (including supported employment), continuing adult education, adults services, independent living or community participation. The coordinated set of activities shall be based upon the individual student's needs, taking into account the student's preferences and interests and shall include instruction, community experiences, the development of employment and other post-school adult living objectives, and, if appropriate, acquisition of daily living skills and functional vocational evaluation. 
Table 1.

Key Legislative Definitions in Technology and Transition-continued

Definition of Transition Services: IDE+ 1997 (P.L.101-17)

a) ...a coordinated set of activities for a student with a disability that-

1) Is designed within an outcome-oriented process that promotes movement from school to post- school activities, including secondary education, vocational training, integrated employment (including supported employment), continuing and adult education, adult services, independent living, or community participation;

2) Is based on the individual student's needs, taking into account the student's preferences and interests; and 3) Includes-(i) Instruction; (ii) Related services; (iii) Community experiences; (iv) The development of employment and other post school adult living objectives; ( $v$ ) If appropriate, acquisition of daily living skills and functional vocational evaluation.

b) Transition services for students with disabilities may be special education, if provided as specially designed instruction, or related services, if required to assist a student with a disability to benefit from special education.

Brown, 1989; Clark \& Kolstoe, 1995; deFur \& Patton, 1999; Halpern, 1994; Sitlington, Neubert, \& Leconte, 1997) and instructional services and AT (e.g., Church and Glennen, 1992; Cook \& Hussey, 1995; Gray, Quatrano, \& Lieberman, 1998; Lewis, 1995; Lindsey, 1993; Woodward \& Reith, 1997). Special education and transition legislation helped clarify definitions, services, and legal obligations of transition and technology-related services; however, little has been done to formally integrate these seemingly unique disciplines.

Inherently, there are striking similarities in the fields of transition and AT. The major foci of both fields are much the same: future environments and independence within those environments and the use of effective methodologies to enhance functionally relevant knowledge and skills for all students with disabilities (Fisher, 1999). Shared horizons for both the areas of transition and technology rest in the need for cooperation and collaboration between professionals and agencies in IEP development, transition, and instructional planning.

\section{Building a Shared Perspective of Technology and Transition}

For many students, the goals of technology and transition are intertwined; goals in one area often cannot be achieved without the collaborative planning of both disciplines. For example, for some individuals, the ability to communicate effectively (a skill that cuts across all transition environments) may only be possible through technology; or, access to job site or the accommodations needed to accomplish the job may not be possible 
Table 2

Service Components in Assistive Technology (AT) and Transition SPECTRLM OF SERVICES INCLUDED IN AT (THE TECHNOLOGY ACT) (PL 100-407)
(a) functional assessment
(b) procedures regarding the acquisition and purchasing of AT devices;
(c) customized selection, design, pairing, and maintenance of existing AT equipment;
(d) coordination of AT and AT-related services with other therapies;
(e) professional training of AT consumers and/or their family members;
(f) and training and technical assistance for professionals involved with individuals with disabilities using AT

TRANSITION SERVICE COMPONENTS (IDEA) (PL 101-476)

(a) functional assessment of daily living skills, career development, and prevocational and vocational skills;

(b) beginning at age 16 and thereafter, mandatory yearly consideration of transition services in every student's IEP;

(c) transition services must be a "coordinated set of activities" individualized for each student;

(d) that transition service be coordinated with other community service agencies involved in secondary and post-secondary services; and

(e) that the instructional delivery of transition services could be provided by schools as well as related service providers not necessarily affiliated with the public schools.

without the assistance of technology. In contemplating new and unique transition environments, we may first see the need for AT when a student's transition plan is created. This framework surrounds the student's next environments-occupational awareness and exploration programs, employment, postsecondary opportunities, social networks, the community and independent living (see Blackhurst, Lahm, Harrison, \& Chandler, this issue). Within this framework, several commonalties emerge.

\section{Self-determination}

In the practice of both fields, the importance of teaching self-determination skills cannot be overstated. How else can we assure that the personal choices about AT are woven into transition plans? Because technology changes so rapidly, devices fall into disrepair, and environments rapidly change, an individual without sufficient self-determination skills may soon find him/herself without adequate technology to improve his/her life conditions. Just as environments and opportunities change for an individual, so will the technology needed to advance and adapt in new situations. If students leave our watch without the empowering knowledge of personal interests, strengths and needs, combined with the self-advocacy to express these 
attributes, we will have missed the mark. Articles in this issue by AndersonInman, Knox-Quinn and Szymanski, and another by Parette, express similar concerns along with suggestions for capitalizing on the known strengths and preferences of individuals.

\section{Planning for Future Environments}

Another piece of common ground between transition and technology can be found in the similarities that exist in legislation regarding AT and transition planning. For example, the requirements in transition planning for long-range services can be a window to the needs for AT services or devices. The article by Blackhurst and his colleagues provides a picture of how future environments can be used to frame technology decisions.

\section{Interagency Planning}

Another similarity that the fields of technology and transition share is in interagency planning. Both fields require the cooperation and planning of agencies that will carry on the work after school years are completed. Perhaps the most difficult problem that students and their families face in the transition to adult lives is obtaining services after school. The reason for these difficulties is apparent: while school services are regulated, required, and known, adult services are not mandated. Compounding the perplexing maze of services is the fact that families may be unaware of services to which they may be eligible. In other cases, even though the adult service may be a known entity, the waiting lists are long or services simply are unavailable (Ferguson, Ferguson \& Jones, 1993).

\section{Families and Parent-School Partnerships}

The relationships that we build with families are pivotal to the success of transition planning. Bruininks, Thurlow and Ysseldyke (1992) reported that families often are the mainstays in a student's life, and in many instances, provide lifelong support. More often than not, this support includes the responsibility of selecting and maintaining technology devices. "Families carry the perspective of past and future from one environment to the next environment; they alone have seen the individual in all of life's settings" (Fisher, 1999, p. 329). The article by Parette points out that families and cultural considerations are central to the planning processes of technology and transition.

\section{Inclusion and Progress in the General Education Curriculum}

The Secretary's Commission on Achieving Necessary Skills (SCANS) report (1991) underscored the importance of applied academics for all students, as well as listening and speaking, thinking skills, and problem solving. More recently, the 1997 amendments to IDEA require students to show 
progress in the regular curricula, with a statement of the support services needed to keep them in the regular curriculum wherever possible. Anderson-Inman et al.'s article demonstrates how AT can be used with great benefit in achieving curriculum and instructional objectives.

As we plan toward graduation and the transition to postsecondary education or careers, it is evident that supports offered to achieve these goals should include the AT needed to ensure success in the regular curriculum. The National Council on Disability (Morris, 1992, p. 5) discovered that "... with the assistance of technology, almost three-quarters of school-age children were able to remain in a regular classroom... [and] 45 percent of school-age children were able to reduce school-related services." Recent legislation has not only identified AT as a related service, but has included a statement requiring school districts to furnish supplementary aids and services" ... which are to be made available in regular education classes and other education-related settings" that "enable children with disabilities to be educated with their nondisabled peers to the maximum extent appropriate." (emphasis added) (20 U.S.C. $\$ 1401$ (29).

Even with the emphasis on the regular curriculum, service providers, families and students must be able to extract life skills instruction to meet individual needs. Recognizing that these needs will differ from needs of other students, the response must involve curriculum adaptation, modifications, and experience in real life settings (Clark, Carlson, Fisher, Cook, \& D'Alonzo, 1991; Clark, et al., 1994), which will at times require AT.

\section{Supporting Transition Through Technology}

Exploring technology applications within the transition framework is a natural development and extension of best practices, which directs consideration of the necessary technology to support the student in the next environments to which he or she will transition from the educational setting. With independence as an important transition goal, the integration of technology that (a) allows access to curriculum, (b) gives a voice to those who could not communicate, and (c) provides heightened mobility and permits multiple employment opportunities, can immeasurably enrich the lives of people with disabilities.

One of the first steps in building a perspective on technology and transition comes through constructing a functional statement merging the language and principles reflected in both legal definitions. Accordingly, we propose the following statement as a starting point.

The concept of technology and transition represents any application of technology, assistive or instructional, that (a) facilitates or enhances the process of persons with disabilities moving from school to specific post-school environ- 
ments and/or (b) assists the growth of a person's ability to make choices, live, learn, work, and plav more independently in the community:

A second step is to recognize that the aforementioned statement reflects a comprehensive perspective that can be inferred even when the concepts of technology and transition are treated separately. For example, depending on one's perspective or interest, the concept of transition might call attention to the environments in which the individual functions, the knowledge and skills required of the individual to function in specific transition environments, or the activities and processes that are associated with the individual's transition from school to the postsecondary environment. Clearly, the concept of transition cannot be defined by a single variable or factor, and it can mean different things to different professionals.

As the result of IDEA's definition of AT and AT services, the prevailing view of technology in special education focuses its application to improve an individual's functionality. Another equally alternative perspective might include consideration of how technology is used as an instructional tool to facilitate student learning. In this issue Blackhurst et al. provide additional ways of defining technology relative to persons with disabilities. Thus, like the concept of transition, the concept of technology in special education (and transition) is not defined by a single variable or factor, but should rather be considered as an integrated and uniform concept.

A third step in constructing a shared perspective of technology and transition begins from a standpoint that focuses primarily on articulating an individual's unique needs; specifically, where either technology and/or transition services are used to provide whatever unique physical, cognitive, or procedural supports that become a part of an individuals'skill repitore. This focus still addresses the careful selection of supports (whether technological or transitional) that improve individuals' functionality, but it directs emphasis away from pure consideration of "technology devices" or "transition environments" as the starting point of conceptualizing technology and transition.

\section{Perspectives on Technology and Transition}

It is important to understand that our effort in this topical issue is to present a viewpoint on technology and transition in a way that calls attention to unique factors and/or issues when considering both domains contemporaneously. Certainly, the extant literature contains a wealth of information that helps us understand each domain by itself as a separate entity. Yet if we adopt a traditional statement from Gestalt psychology, "the whole is more than the sum of the parts," our foremost grasp of technology and transition comes to light with a merger and blending of both domains. 


\section{Technology Planning Should be Aligned with Transition Competencies}

The topical issue begins by presenting Blackhurst et al.'s article on a framework for aligning technology with transition competencies. The authors examine how technology aligns with various categories of human functions that relate to environmental challenges and transition services. According to Blackhurst et al., individuals with disabilities face a variety of unique challenges in their daily lives. Transition services, and assistive and instructional technologies represent domains that naturally combine with one another to provide individuals with disabilities a set of supports that enable and support functionally relevant behaviors. These behaviors assist individuals to respond to environmental demands, and result in outcomes that impact their success performance of transition competencies.

The Blackhurst et al. framework provides examples that address transition and technology equally well from a variety of perspectives. Most importantly, the article helps us understand and consider the identification and selection of technology and transition competencies from a system's perspective. Using technology to enhance transition planning and the transition process is not simply saying that technology "A" assists transition competency "X." Each individual's use of technology in transition represents a unique combination of ecological and social factors in a system where these factors interact and influence each other in potentially complex ways. Blackhurst et al.'s unique framework for aligning technology with transition competencies cuts across time, individual characteristics and situations, and transition environments to significantly impact stakeholders' and end users' decisions and actions.

\section{Technology and Transition Involves Social Components and Issues}

Many factors and outcomes of technology and transition have significant social effects. This perspective is demonstrated throughout Parette's article on transition and AT planning as it relates to families of various cultures. Through Parette's careful analysis of cultural issues and various perspectives and predispositions of different family groups, the importance of familycentered planning is emphasized relative to technology in transition services. Despite good intentions, functional relevance, and proposed outcomes of using technology in transition planning, Parette cautions us that families across different cultures may not eagerly embrace the use of AT. For example, AT decisions and services may have a negative impact on some family functions, because factors and behaviors associated with using AT may be at odds with certain family values and belief systems. The potential for increased personal independence as the result of using AT may not be highly valued by other family members, or AT may even be viewed as accentuating a disabling condition rather than positively expanding the user's abili- 
ties. Moreover, family members may have varied reactions to the amount of perceived time and support needed with respect to $\mathrm{AT}$ training.

Parette concludes that when making AT recommendations with respect to the transition process, we must understand that our decisions will impact families in ways that may create unique cultural, ethnic, and social sensitivity issues or circumstances. We must therefore be prepared, among other things, to address relevant family concerns regarding AT and the transition planning process in ways defined as relevant by the family, not the service provider. Technology and transition providers must offer culturally sensitive and extensive communication and be prepared to meet differing information needs of families. Professionals must understand that their preferences for AT may not automatically result in the family member with the disability receiving what experts might clearly define as "best practice" and/or the "most functionally relevant" support.

\section{Computer-supported Studying Promotes Postsecondary Transition}

There are many situations where technology can provide a useful "tool" to individuals who have to perform specific tasks to be successful in transition. In their article on computer supported studying in the context of post secondary transition, Anderson-Inman et al. report that a variety of students with learning disabilities who transition from high school to college and university settings are at risk for experiencing future academic difficulties. The authors observe that many of the postsecondary challenges facing students with learning disabilities, such as time management, reading and comprehension, and integration and synthesis of information, rely on students successfully using cognitive and self-management strategies. Unfortunately, many students transitioning out of high school have never learned appropriate postsecondary academic problem-solving strategies.

Anderson-Inman et al. propose that one solution for successful transition is to empower students by providing access to a variety of computer-based tools. They describe three projects and give examples of how individual students-each with unique learning disabilities-used technology to master a set of academic tasks they were formerly unable to accomplish. Each student was taught to use a specific set of software tools and techniques to support his/her management of the reading, writing, and study demands of postsecondary settings. Anderson-Inman et al.'s perspective on technology and transition emphasizes the unique and individualized situation, and that computer-based tools should be delivered via a systematic instructional program that (a) addresses computer-based strategies to compensate for limitations from the disability, (b) utilizes existing learning strengths, and (c) promotes self-determination and independence. 


\section{Video-based Simulations Can Promote Community-based Training and Transition}

It often has been reported that one of the benefits to using computers in education comes from their ability to simulate real life activities and use graphics and sounds to embellish content. The article by Wissick, Gardner, and Langone describes ways that transition-related contextual barriers can be removed through the use of technology. The authors discuss how opportunities for community-based training can be enhanced through the use of anchored instruction and multimedia. Using properly designed multimedia technology that incorporates video-based depiction and simulation of realistic/natural learning environments and performance of authentic outcomes, students may be able to learn functionally relevant transition-related concepts or skills more effectively. In this case, either as a precursor to community-based learning and/or as a way to promote maintenance, the context of the community is simulated via technology applications in a classroom environment. For example, rather than going shopping in the community, students go shopping via an interactive multimedia-based computer simulation.

Wissick et al. are careful to point out that the ultimate goal of using simulations are not to supplant performing relevant skills in the real world, but to use technology and multimedia as a means to replicate community situations that enhance the learning environment for students and teachers. Multimedia-based simulations, relying on features of authenticity and anchored instruction, can assist learners in becoming as independent as possible within the simulation classroom environment. In turn, new, simulationbased skills are practiced in the real world to promote smoother and more reliable generalization. In order to provide effective instruction using simulations, designers and teachers must consider a variety of specific factors related to instruction design and delivery, which are discussed in the article.

\section{Teachers can be Prepared for Transition Services via the World Wide Web}

In the article by Smith and Jones, technology is used to enhance instruction and remove barriers to instruction for service providers in the transition field. By accessing web-based scenarios depicting authentic case studies of students facing transition dilemmas, participants have the opportunity to confront issues and to pose solutions to these problems in real time. The authors utilize the dynamic nature of the web to present information and mediate group discussion and problem solving. Through their web site, "Transitions," preservice and inservice teachers are developing a better understanding regarding the concepts and principles behind transition as they become active participants in an electronic forum, virtually linked with other students.

One of the things that is significant about the way that Smith and Jones are delivering instruction that addresses the transition process has to do 
with the virtual nature of their web-based approach. Accessing the world wide web and the "Transitions" web site provides diverse learners a forum to explore, experience, and construct a firm understanding of transition from any location in the world. The "Transitions" web site provides something that these individuals may not be able to obtain in a traditional classroom or training environment - the ability to achieve anonymity. As Smith and Jones describe, learners construct a deeper understanding about person with disabilities and transition because communication between learners becomes less inhibited, discourse between individuals is shared and enhanced, and they experience multiple perspectives to problems and issues.

\section{Visual Enhancement Makes Transition Information More Meaningful for Deaf Persons}

An example of how technology can be used to remove individual barriers caused by deafness is discussed by Davis. Davis introduces a clear and compelling problem: the principal medium through which deaf learners acquire information is through signed communication, but traditional transition curricular materials and assessment tools do not provide this capability. The research described by Davis includes a video orientation to assist both multimedia instruction and transition planning for deaf students and focuses on the importance of providing different forms of visual access and enhancement to support deaf students' performance of transition competencies.

Davis describes ways in which technology can successfully improve deaf students' transition skills. By adding signed communication to video tape, videodisc, CD-ROM-based, and digital video applications, deaf students achieve significantly higher understanding and comprehension of transition-related information. The increased comprehension greatly improves the reliability and validity of the testing situation and provides a more accurate data understanding of a student's transition competencies. In instructional situations, curriculum materials that deliver signed information using CD-ROM and/or digital video can be combined with computer managed instruction to create an effective and interactive learning environment in which to teach transition-related competencies.

\section{DISCUSSION}

Exploring common horizons of transition and technology has great significance for the future of these shared disciplines. The converging paths of the two fields forms a much broader application and influence on the lives of people with disabilities than each concept considered in isolation or separately. As we examined the articles included in this issue, we found several emerging themes which have implications for practice and for future investigation. 
First, using technology to enhance instruction (both for students and educators) is predominant. In particular, given the recent thrust of inclusion and of progress in the general education curriculum, increased attention to academic headway, accommodations, and the related services that support transition to postsecondary environments should be anticipated. What is both exciting and reassuring in many of these articles is the demonstration that the field of special education is developing and perfecting innovative applications of various types of technology in functionally relevant ways. These applications take the technology far beyond an elementary use to a use which-by careful analysis, expertise, and reflection-represents an accurate and creative way to address transition dilemmas.

Second, the importance of the questions both raised and considered as we bring new technology-based tools to transition planning is paramount. Questions of personal choice, family considerations, and self-determination certainly deserve attention. Research examining the effectiveness of technologies "chosen" vs. technologies "prescribed" or "available" would contribute valuable information to those performing technology assessment in transition environments. Undoubtedly there will be more questions of the category that Parette raises: What really can be acceptable for individuals and their AT preferences? Will devices continue to draw undue attention to individuals, or are we rapidly approaching the time when robotics, simulated voices, replaceable body parts, and electronic circuitry become so commonplace that no second looks are given?

Third, the use of video-based technology in transition assessment and learning activities is increasing. The capability to bring realism to structured assessment and learning activities may well revive the old controversy between simulated and situational assessment. As virtual worlds become more prevalent and accessible, it is very likely that assessment of transition skills will be accomplished with picture-perfect accuracy and in simulated contexts that are matched closely to the "real-life" setting in which the student will be asked to function. Davis' writing regarding the importance of using visual models and signing when administering computer-based assessment, as well as Wissick et al.'s discussion concerning anchored instruction and appropriate role models, provide such viewpoints. The effectiveness of using technology in transition-related assessment and instruction is not just related to how well a computer manages assessment and instruction, but in how naturally and meaningfully the information is presented to the individual learner.

Finally, while political agendas continue to shape the direction and extent of technology assistance, there exists a pressing need to reach joint understanding of the union of technology and transition. The article by Blackhurst et al. provides our field with a model that can be used in a con- 
sistent manner to not only understand how technology is linked to transition competencies, but how decisions in the technology and transition planning process take place.

\section{SUMMARY}

Starting in the 1980 s, system change initiatives sponsored by the United States Department of Education exerted a great deal of influence upon education. Included among these were model demonstration and research programs, interagency assistance and significant policy directives. Transition implementation, and more recently, AT policies and practices have benefitted from these impetuses. In a variety of ways, both the transition and technology fields have continued through the 1990s in a roughly synchronous fashion.

In the articles that follow, the reader will notice other barriers-some mentioned specifically and some implied - to full implementation of AT in classrooms and in the process of transition (e.g., expense of technology, training demands, rapid hardware and software developments). Keep in mind that reaching the full power of technology has much more to do with the people involved than with the hardware or what we see as perspective of or obstacles to implementation. Let us not forget that, "As educators, specialists, and advocates we need to stay informed and open to new technologies and to ways of teaching and guiding the transition into the 21st century. We must keep in mind that the psychology of change is always much more difficult than the technology" (Fisher, in press, p. 309). We hope that you will enjoy this issue and that the work described herein becomes an impetus for this type of change.

\section{REFERENCES}

Adult and Medical Services Commission of the Kansas Department of Social and Rehabilitation Services. (July, 1998). Education and Medically Necessary Services: An Informational Brochure About Services to Increase Your Child's Success in School. (MS-2200) [Brochure]. Topeka KS: Author.

Americans with Disabilities Act of 1990, P.L. 101-336. 42 U.S.C. $\$ 12101$ et seq.

Apple, M.W., \& Zenk, C. (1996). Is education to blame for our economic problems? In M. Apple, Cultural politics and education. (pp. 68-90). New York, NY: Teachers College Press.

Behrmann, M. (1984). Handbook of microcomputers in special education. San Diego, CA: College-Hill.

Bell, J.K. \& Blackhurst, A.K. (in press). National survey of state department of education assistive technology policies. Journal of Special Education Technology.

Berkell, D. \& Brown, J.N. (1989). Transitions from school to work for persons with divalsilities. New York: Longman.

Blackhurst, A. E., \& Hofmeister, A. M. (1980). Technology in special education. In R. D. Kneedler \& S. G. Tarver (Eds.), Changing perspectives in special education. (Pp.156-182). Columbus, $\mathrm{OH}$ : Merrill.

Bruininks, R., Thurlow, M.L., \& Ysseldyke, J.E. (1992). Assessing the right outcomes: 
Prospects for improving education for youth with disabilities. Education and Training in Mental Retardation, 27, 93-100.

Carl D. Perkins Vocational Education Act of 1984, P.L. 98-524. 20 U.S.C.

Carl D. Perkins Vocational and Applied Technology Education Act of 1990, P.L. 101-392.20 U.S.C. $\$ 2301$.

Church, G, \& Glennen, S. (1992). The handbook on assistive technology. San Diego, CA: Singular.

Clark, G.M., Carlson, B.C., Fisher, S.K., Cook, I.D., \& D'Alonzo, B.J. (1991). Career development for students with disabilities in elementary schools: A position statement of the Division on Career Development. Career Development of Exceptional Individuals, 14, 109-120.

Clark, G.M., Field, S., Patton, J.R. Brolin, D. \& Sitlington, P.L. (1994 ). Life skills instruction: A necessary component for all students with disabilities: A position statement of the Division on Career Development and Transition, Career Development for Exceptional Individuals, 17, 125-133.

Clark, G.M. \& Knowlton, H.E. (Eds.). (1987). The transition from school to adult life. [Special Issue]. Exceptional Children, 53.

Clark, G.M. \& Kolstoe (1995). Career Development and transition education for adolescents with disabilities. Needham Heights, MA: Allyn \& Bacon.

Cook, A.M., \& Hussey, S.M. (1995). Assistive Technologies: Principles and Practices. St. Louis, MO: Mosby.

deFur, S. \& Patton, J. (Eds.) (1999). Transition and school-Based services: Interdisciplinary perspectives for enhancing the transition process. Austin: PRO-ED.

Education for All Handicapped Children Act of 1975, P.L. 94-142.

Education for All Handicapped Children Act of 1983, P.L. 98-199.

Ellis, S. E., \& Sabornie, E.J. (1986). Effective instruction and microcomputers: Promises, practices, and preliminary findings. Focus on Exceptional Children, 19, 1-16.

Fisher, S.K. (1999) Assistive Technology. In S. deFur \& J. Patton (eds.) Transition and schoolbased services: Interdisciplinary perspectives for enhancing the transition process. (pp. 309-385). Austin: PRO-ED.

Ferguson, P.M., Ferguson, D.L., \& Jones, D. (1993). Generations of hope: Parental perspectives on the transition of their children with severe retardation from school to adult life. The Journal of the Association for Persons with Severe Handicaps, 13, 177-187.

Galvin, J. C., \& Wodshall, R.A. (1996). AT-related legislation and policies. In Galvin, J. C., \& Scherer, M. J. (Eds). Evaluating, Selecting, and Using Appropriate AT (pp. 315 - 344). Gaithersburg, MD: Aspen.

Gray, D. B., Quatrano, L. A., \& Lieberman, M. L. (1998). Designing and using assistive technology. Baltimore, MD: Brookes.

Hager, R. (1998, September). Vocational rehabilitation agencies and assistive technology. Paper presented at The AT Conference, Topeka, Kansas.

Halpern, A.S. (1985). Transition: A look at the foundations. Exceptional Children, 51, 479-486.

Halpern, A.S. (1994). The transition of youth with disabilities to adult life: A position statement of the Division on Career Development and Transition, The Council for Exceptional Children. Career Development for Exceptional Individuals, 17, 115-132.

Hasselbring, T., Goin, L. \& Bransford, J. (1988). Developing math automaticity in learning handicapped children: the role of computerized drill and practice. Focus on Exceptional Children 20, 1-7.

Hasazi, S.B., Gordon, L.R., \& Roe, C.A. (1985). Factors associated with the employment status of handicapped youth exiting from high school from 1979 to 1983. Exceptional Children, 51, 455-569.

Individuals with Disabilities Education Act of 1990, P.L. 101-476. (October 30, 1990). Title 20, U.S.C. 1400 et seq.

Individuals with Disabilities Education Act of 1997, P.L. 105.17 (June 4, 1997). 20 U.S.C. $\S$ 1400 et seq.

Jordon, J.B. \& Thomas, M.D. (Eds.). (1982). Microcomputers' place in special education [Special Issue]. Exceptional Children, 49(2). 
Julnes, R. E. \& Brown, S. E. (1993). The legal mandate to provide AT in special education programming. West's Education Law Reporter, 82, 737-48.

Lewis, R. B. (1995). Special education technology: Classroom applications. Pacific Grove: Brooks/Cole.

Lindsey, J. (1993). Computers and exceptional individuals (2nd Ed.). Austin. Texas: PRO-ED.

Mithaug, D.E., Horiuchi, C.N., \& Fanning, P.N. (1985). A report on the Colorado statewide follow-up survey of special education students. Exceptional Children, 51, 39-7114

Morris, M. (1992). Policy in the making: The right to take AT home fiom rhon. AT Quarterly: RESNA Technical Assistance Project, 3, 5.

Razeghi, J., Kokaska, C., Gruenhagen, K. \& Fair, G. (1987). The transition of routh with disabilities to adult life: A position statement of the Division on Career Development. The Council for Exceptional Children. April. Reston, VA: The Council for Exceptional Children.

Rehabilitation Act of 1973, 29 U.S.C. $\$ 701$ et seq.

Rehabilitation Act Amendments of 1992, 29 U.S.C. $\$ 701$ et seq.

Rehabilitation Act Amendments of 1998, 29 U.S.C. $\$ 798$ et seq.

Rehabilitation Services Administration (RSA) (August, 1998). Polio Diretice. RS L.PI)-(97-()4.

Reid, J. E. (1994). All states survey of facilitating practices in special education. [L npublished Manuscript], Reno, NV: Nevada AT. Collaborative.

Rieth, H. J., Bahr, C.M., Polsgrove, L., Okolo, C.M. and Eckhert, R. (1987). The effects of microcomputers on the secondary special education classroom ecology. Journal of Special Education Technology, 8, 36-45.

School-to-Work Opportunities Act of 1994, P.L. 103-239.

Secretary's Commission on Achieving Necessary Skills (1991, June). What atrot retuim of schools: A SCANS report for Americans 2000. Washington, DC: Department of I abor.

Sitlington, P.L., Neubert, D. \& Leconte, P.J. (1997). Transition Assessment: The Position of the Division on Career Development and Transition. Career Development for Exreftional Individuals, 20, 69-79.

Technology-Related Assistance of Individuals with Disabilities Act of 1988. 29 L.S.C. \$290I et seq.

Will, M. (1984). OSERS program for the transition of youth with divililitie: Bridges from show to working life. Washington, DC: Office of Special Education and Rehabilitative Services. US Department of Education.

Woodward, J. \& Reith, H. (1997). A historical review of technology research in special education. Review of Education Research, 67, 503-536.

Zigmond, N., \& Thornton, H. (1985). Follow-up of post secondary age learning disabled graduates and dropouts. Learning Disabilities Research, 1, 50-55.

\section{AUTHOR INFORMATION}

Sherrilyn K. Fisher is Coordinator of Staff Development and Curriculum for the Wyandotte Comprehensive Special Education Cooperative in Kansas City, Kansas (District \#500). J. Emmett Gardner is an associate professor in the Department of Educational Psychology at The University of Oklahoma.

\section{CONTACT INFORMATION}

Dr. Sherrilyn K. Fisher, Wyandotte Comprehensive Special Frluation Cooperative, 600 Minnesota Ave.. Kansas C.ity, Kansas 66101: email: shfishe@gw.kckps.k12.ks.us. 